\title{
Combined non-isotopic in situ hybridisation and immunohistochemistry on routine paraffin wax embedded tissue: identification of cell type infected by human parvovirus and demonstration of cytomegalovirus DNA and antigen in renal infection
}

\author{
H J Porter, A Heryet, A M Quantrill, K A Fleming
}

\begin{abstract}
A method for combined immunohistochemistry using alkaline phosphatase antialkaline phosphatase (APAAP) and in situ hybridisation using biotinylated probes was developed. The method requires no change to either technique and no additional procedures between them. The procedure was able to show the cell types involved in parvovirus infection of the fetus. The efficiency of immunohistochemistry and in situ hybridisation for the detection of cytomegalovirus in kidney were also compared: occasional cells contained cytomegalovirus DNA but not antigen.

The method is rapid, straightforward, and has wide applications in the study of viral infections, genes, and gene products in tissue sections because it permits the combined demonstration of antigen and nucleic acid on the same section in routine clinical material.
\end{abstract}

Immunohistochemistry for antigen detection has been used very successfully in the examination of histological and cytological preparations for many different clinical and research purposes. In situ hybridisation for nucleic acids has been developed more recently and is also being increasingly used in clinical and research laboratories. ${ }^{1}$ While these two procedures are both analogous and complementary, and can be done on serial preparations, there are certain situations in which combined use of the two techniques on the same preparation can be advantageous. For instance, demonstration of protein in a cell does not necessarily mean that the cell has synthesised that protein; it may have absorbed it from the environment. Simultaneous demonstration of mRNA and antigen, however, would provide unequivocal proof of synthesis. An example of this is the detection of immunoglobulin in Reed Sternberg cells in Hodgkin's disease. Controversy persists about whether these proteins are synthesised or absorbed by these cells. ${ }^{2}$ Another use of combined in situ hybridisation/immunohistochemistry would be in the identification of cell types containing nucleic acid. For example, unequivocal assignment of the cell type involved in a viral infection can be achieved by combining in situ hybridisation for viral nucleic acid and immunohistochemistry for cell type. The presence of the slow virus Visna in oligodendrocytes has been shown by Hasse. ${ }^{3}$

While combined in situ hybridisation/immunohistochemistry has been reported previously, ${ }^{3-6}$ these authors used autoradiography for in situ hybridisation and peroxidase/diaminobenzidine (DAB) for immunohistochemistry. This required additional steps between the two procedures to prevent nonspecific binding of probe to the DAB reaction product. Furthermore, peroxidase/DAB is only one of many immunohistochemistry methods available and others have advantages of increased sensitivity with fewer non-specific staining problems. The use of radioisotopes for in situ hybridisation also has disadvantages, some of which can be overcome by probes with non-radioactive labels. ${ }^{7}$

We describe a straightforward method combining immunohistochemistry with the alkaline phosphatase antialkaline phosphatase (APAAP) technique, followed by in situ hybridisation using biotinylated probes. The method is rapid and requires no additional procedures between the immunohistochemistry and in situ hybridisation. We have used the method to study the cell type involved in parvovirus infection of the fetus ${ }^{89}$ and to compare the sensitivity of in situ hybridisation with immunohistochemistry for the detection of cytomegalovirus (CMV) infection in tissue sections. We also compared the relative efficiency of several substrates and chromogens for both peroxidase and alkaline phosphatase in the combined procedures.

\section{Methods}

Kidney from a neonate who died shortly after birth from disseminated $\mathrm{CMV}$ infection was used. CMV was cultured from the placenta; serology from both the baby and the mother showed CMV IgM with a titre of greater than 1256, and characteristic viral inclusions were present in kidney, lung, heart, brain and placenta. For the parvovirus study, tissues from heart, lung, brain, spleen, pancreas, 


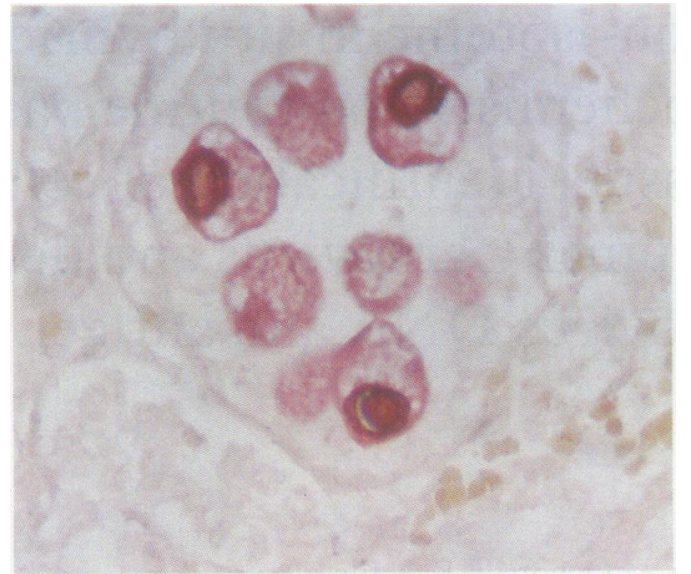

Figure 1 CMV infected cell stained with monoclonal antibody $\mathrm{CCH}_{2}$ and $A P A A P$ with acid fuchsin.

kidney, adrenal and placenta from a fetus previously shown to be infected by parvovirus by in situ hybridisation were used.

Sections $5 \mu \mathrm{m}$ thick from formalin fixed, paraffin wax embedded tissue were cut on to slides coated with $2 \%$ aminopropyltriethoxysilane in acetone ${ }^{9}$ and baked at $80^{\circ} \mathrm{C}$ for two hours. Each slide had two sections on it and these were stained using the standard APAAP technique $^{10}$ and either acid fuchsin or fast red chromogen. In the CMV study slides were stained with monoclonal antibody $\mathrm{CCH}_{2}$ for CMV (Dako) or monoclonal antibody RET 40F for erythrocytes. ${ }^{11}$ To investigate the cell type involved in fetal parvovirus infection the following monoclonal antibodies were used:

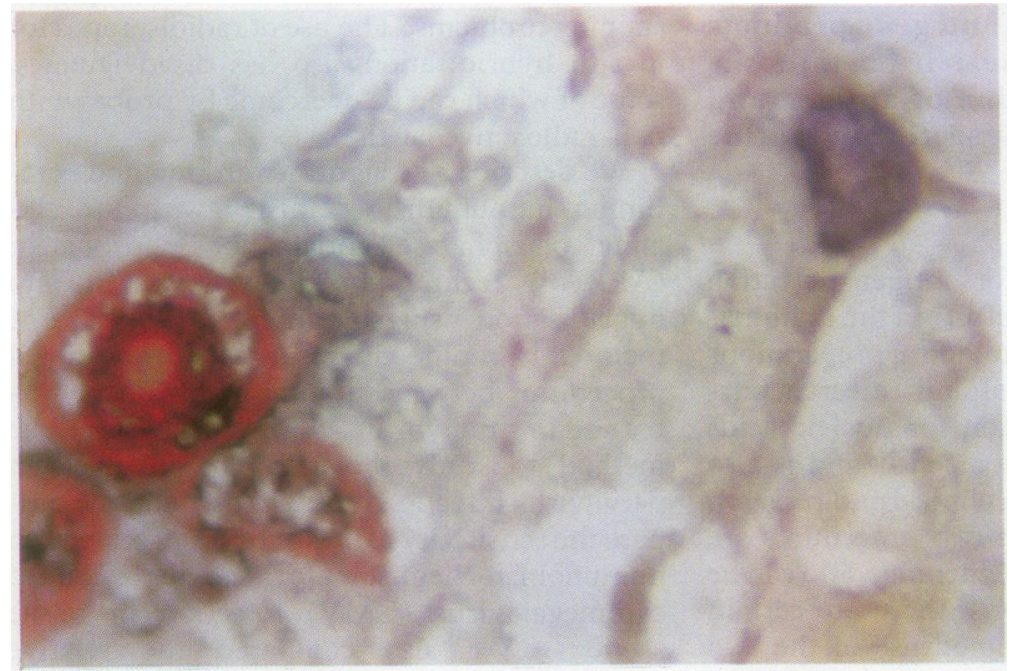

Figure 3 Combined immunohistochemistry (with antibody $\mathrm{CCH}_{2}$ ) and in situ hybridisation (for $C M V D N A$ ) showing cell positive by in situ hybridisation alone.
RET 40F as in the CMV case; a combination of PD7/26 and 2B11 (DAKO-LC) for leucocytes; MAC 387 (Dako) for macrophages; factor VIII (Dako) for endothelial cells; CAM 5.2 (Becton Dickinson) for epithelium; and DER11 (Dako) for myocardial fibres. The immunoperoxidase method was tried using DAB, aminoethylcarbazol, and 4 chloro-1-naphthol as alternative chromogens. All the sections were pretreated with trypsin before immunohistochemistry except for those used for leucocyte monoclonal antibodies.

After immunohistochemistry the slides were

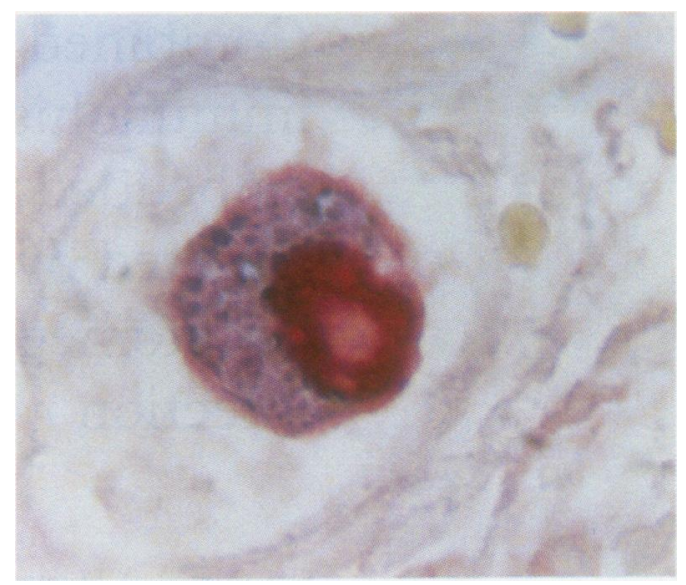

Figure $2 C M V$ infected cell stained with monoclonal antibody $\mathrm{CCH}_{2}$ and $\mathrm{APAAP}$ (red) followed by in situ hybridisation for CMV DNA (brown).

stored under various conditions. These included (i) air drying and storage at room temperature until use (one, two, or seven days); (ii) storage in phosphate buffered saline at $4^{\circ} \mathrm{C}$ for periods up to 40 hours. In situ hybridisation was performed using biotinylated probes and the method described previously. ${ }^{9}$ The probes were CMV (Enzo), PYT 104 (Peter Tattershall, Yale) for parvovirus and plasmid pBR 322 as the negative control.

\section{Results}

The storage conditions of the sections after immunohistochemistry and before in situ hybridisation were important. Increasing the period of air drying resulted in a reduced in situ hybridisation signal and increased background. Storage at $4{ }^{\circ} \mathrm{C}$ in phosphate buffered saline gave the best results for in situ hybridisation with no decrease in signal within the time tested $(40 \mathrm{~h})$. The APAAP staining was unaffected by the in situ hybridisation procedure, as was the immunoperoxidase method using DAB. The red colour of acid fuchsin in napthol ASBI phosphate gave good contrast with the brown/black deposits of the in situ hybridisation, but the brown colour of DAB was difficult to distinguish from the in situ hybridisation. Fast red in napthol ASMX phosphate also gave good contrast but was less sensitive than acid fuchsin. Aminoethylcarbazol was less stable than $\mathrm{DAB}$, showed some leaching out during the in situ hybridisation procedure, and tended to look brown rather than red, again resulting in difficulty in distinguishing it from the in situ hybridisation. 4 chloro-1 napthol did not withstand the in situ hybridisation procedure and was completely lost. In situ hybridisation for both probes gave slightly less strong results when preceded by immunohistochemistry but was still easily interpretable.

In general, the monoclonal antibody $\mathrm{CCH}_{2}$ gave strong positive staining of both cytoplasm and nuclei of many (presumably CMV infected) cells (fig 1). In situ hybridisation combined with immunohistochemistry also showed positive staining of nuclei of such cells with granular positivity in the cytoplasm (fig 2). These granules probably represent newly syn- 


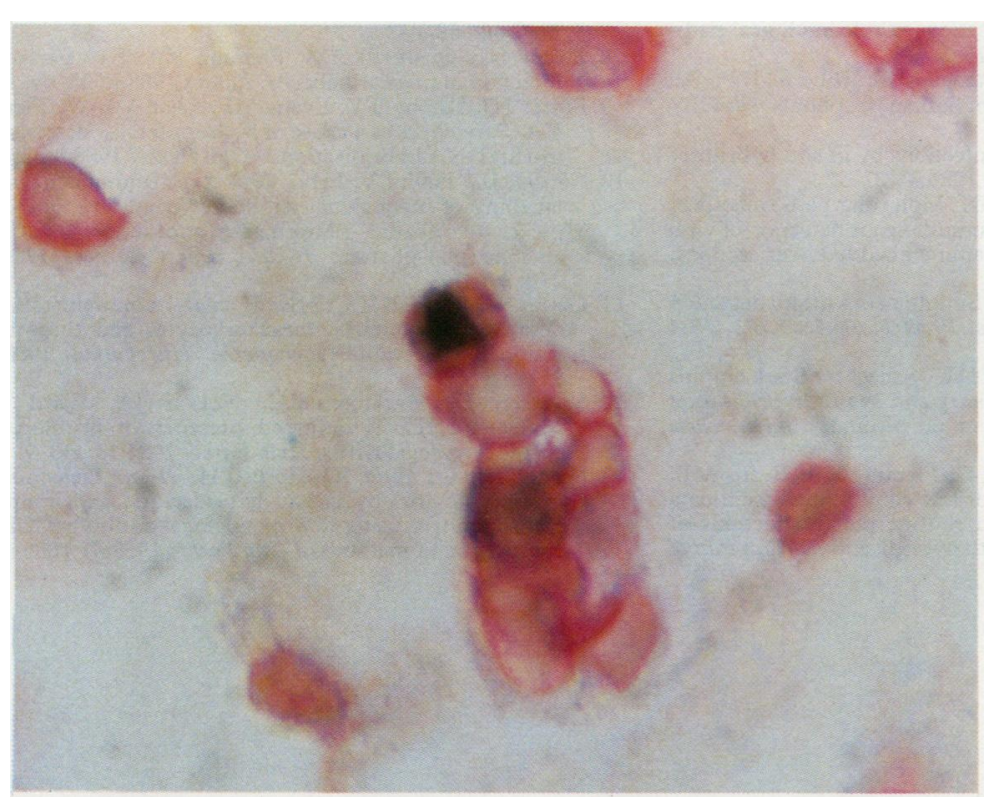

Figure 4 Placenta with erythrocytes stained with monoclonal antibody RET 40F and $A P A A P$ (red) followed by in situ hybridisation for parvovirus DNA (brown/black).

thesised virus particles which are known to accumulate in the cytoplasm of infected cells before release. Some cells positive by $\mathrm{CCH}_{2}$, however, were negative by in situ hybridisation, while more infrequently, cells positive by in situ hybridisation were negative with $\mathrm{CCH}_{2}$ (fig 3). In the tissues infected with parvovirus viral DNA was found in erythrocytes (fig 4), macrophages, and occasional myocardial fibres.

\section{Discussion}

The combined use of immunocytochemistry and in situ hybridisation has wide applications; for example, in studying many different aspects of viral infections of cells ${ }^{45}$ and for simultaneous demonstration of a gene and its products. ${ }^{6}$ The method described in this paper is straightforward, requiring no change to the usual methods for either the immunohistochemical staining or in situ hybridisation. There are also no extra procedures between the two methods. This is in contrast to the methods described previously for combined in situ hybridisation (by autoradiography) and for immunohistochemistry, (by peroxidase/DAB) ${ }^{3-6}$ The use of biotinylated probes permits rapid in situ hybridisation, so that the combination of the two techniques only takes two days. Interestingly, the APAAP procedure gave a better contrast with the in situ hybridisation reaction product than peroxidase/DAB as APAAP is a more sensitive technique for immunohistochemistry. We also found that acid fuschin was a more sensitive substrate/chromogen for alkaline phosphatase than fast red. The use of trypsin in the immunohistochemistry did not cause any difficulty with the subsequent pepsin digestion for in situ hybridisation, which was done as normal.

Combined examination of the kidney infected with CMV was undertaken for two reasons. Firstly, it was done to obtain a comparison of the relative sensitivity of the two techniques for detection of virus. It has previously been reported that in situ hybridisation for CMV is more sensitive than standard haematoxylin and eosin. ${ }^{12}$ Subsequently, Niedobitek compared the sensitivity of immunohistochemistry with in situ hybridisation for viral detection using the antibody $\mathrm{CCH}_{2}$ and a CMV probe. ${ }^{13}$ This was done by counting the number of positive cells by each method on serial sections. These authors found slightly more cells positive by $\mathrm{CCH}_{2}$ than with the CMV probe, while both techniques showed more cells than could be seen on haematoxylin and eosin staining. Our results are virtually identical and also showed some cells positive by $\mathrm{CCH}_{2}$ that were negative with the CMV probe. As we observed that the signal for DNA was slightly reduced by the preceding immunohistochemistry for any antigen, it may be that this differential detection of virus by in situ hybridisation and immunohistochemistry would not be found if the procedures were performed separately. For instance, it may be that any or all of the reagents used in the immunohistochemistry (such as trypsin or antibodies), contain trace amounts of nucleases which would reduce the in situ hybridisation signal.

The second reason for examining the infected kidney by combined in situ hybridisation/ immunohistochemistry was to relate the expression of viral protein to the presence of viral DNA. It was therefore of interest that occasional cells were positive for CMV DNA but negative with the antibody. This suggests that these cells were either not synthesising or storing the relevant CMV protein at the time of investigation. Thus the use of combined in situ hybridisation/immunohistochemistry with a panel of monoclonal antibodies may permit correlation of the histopathological features of CMV infection with the production of different proteins, a process which may be relevant to latency and pathogenesis.

In the second part of this investigation examination of the tissues from fetuses infected with parvovirus allowed at least some of the cell types involved to be identified. Thus while parvovirus had previously been thought to infect only nucleated erythrocytes in man, we have shown here that macrophages and myocytes are also infected. It should be noted that although the positive macrophages may have phagocytosed infected erythrocytes, we were not able to show convincingly a separate macrophage nucleus in these cells. Not withstanding this, the finding of parvovirus DNA in myocardial fibres indicates that parvovirus infection is not limited to the red cell series in man.

In conclusion, in situ hybridisation and immunohistochemistry can be combined on routine clinical histopathological samples, and using the method described here, can be performed quickly and with no modifications to either technique. The methods offer a tool which has wide application for research purposes, as evidenced here by the identification of previously unrecognised parvovirus infection of human macrophages and myocardial cells, and for diagnostic work, as in diagnosis of renal CMV infection. 
1 Fleming KA. In situ hybridisation-a role in clinical pathology. J Pathol 1987;153:201-2.

2 Mason DY, Bell JI, Christensson B, Biberfeld P. An Immunohistological study of human lymphoma. Clin Exp Immunol 1980;40:235-48.

3 Haase AT. Analysis of viral infections by in situ hybridisation. J Histochem Cytochem 1986;34:27-32.

4 Blum HE, Haase AT, Vyas GN. Molecular pathogenesis of hepatitis $B$ virus infection: simultaneous detection of viral DNAS and antigens in paraffin embedded liver sections. Lancet 1984;ii:771-5.

5 Brahic M, Haase AT, Cash E. Simultaneous in situ detection of viral RNA and antigens. Proct Natl Acad Sci USA 1984;81:5445-8.

6 Shivers BD, Harlan RE, Pfaff DW, Schachter BS. Combination of immunohistochemistry and in situ hybridisation in the same tissue section of rat pituitary. J Histochem Cytochem 1986;34:39-43.

7 Burns J, Graham AK, Frank C, Fleming KA, Evans MF, McGee J O'D. Detection of low copy human papilloma virus DNA and mRNA in routine paraffin sections of cervix by non-isotopic in situ hybridisation. J Clin Pathol
$1987 ; 40 \cdot 858-64$

8 Porter HJ, Quantrill AM, Fleming KA. B19 parvovirus infection of myocardial cells. Lancet 1988;i:535-6.

9 Porter HJ, Khong TY, Evans MF, Chan VT-W, Fleming KA. Parvovirus as a cause of hydrops fetalis: detection by in-situ DNA hybridisation. J Clin Pathol 1988;41:381-3.

10 Cordell JL, Fallini V, Erber WN et al. Immunoenzymatic labelling of monoclonal antibodies using immune complexes of alkaline phosphatase and monoclonal antialkaline phosphatase. J Histochem Cytochem 1984;32: 219-29.

11 Gatter KC, Cordell JL, Turley H, et al. Immunohistological detection of platelets, megakaryocytes and thrombi in routinely processed specimens. Histopathol 1988;13: routinely.

12 Myerson D, Hackman RC, Nelson JA, Ward DC, McDougal JK. Widespread presence of histologically occult cytomegalovirus. Hum Pathol 1984;15:430-9.

13 Niedobitek G, Finn T, Herbst $\mathrm{H}$, et al. Detection of cytomegalovirus by in-situ hybridisation and immunohistochemistry using new monoclonal antibody $\mathrm{CCH}_{2}:$ a comparison of methods. J Clin Pathol 1988;41:1005-9. 